\title{
The intimacy between sexual traits and Grime's CSR strategies for orchids coexisting in semi-natural calcareous grassland at the Olive Lawn
}

\author{
Simon Pierce $\cdot$ Ilda Vagge $\cdot$ Guido Brusa $\cdot$ \\ Bruno E. L. Cerabolini
}

Received: 15 November 2013/Accepted: 25 February 2014/Published online: 12 March 2014

(C) Springer Science+Business Media Dordrecht 2014

\begin{abstract}
The diversity of orchid species in seminatural calcareous grassland is thought to depend on floral variability. However, differences in primary lifehistory strategy, or the overall suite of functional traits, could also affect coexistence. Both primary strategy (affecting day-to-day survival) and reproductive traits (representing periodic events) have been hypothesized to contribute to a general mechanism regulating the local persistence and relative abundance of species. We recorded species identity at 8,000 points at the centimetre scale along sixteen 5-m long transects at the Olive Lawn, a xeric sand calcareous grassland near Lecco, Italy. Transects allowed the relative abundance and spatial aggregation of Grime's competitor, stresstolerator, ruderal (CSR) strategies to be quantified. Orchid flowering and fruiting phenology was recorded
\end{abstract}

Communicated by Satoki Sakai.

Electronic supplementary material The online version of this article (doi:10.1007/s11258-014-0318-y) contains supplementary material, which is available to authorized users.

S. Pierce $(\bowtie) \cdot$ I. Vagge

Department of Agricultural and Environmental Sciences (DiSAA), University of Milan, Via G. Celoria 2, 20133

Milan, Italy

e-mail: simon.pierce@unimi.it

G. Brusa · B. E. L. Cerabolini

Department of Theoretical and Applied Sciences, University of Insubria, Via J.H. Dunant 3, 21100 Varese, Italy alongside the phenology of graminoid growth. Seven orchid species were present and exhibited a spectrum of strategies spanning two extremes, (1) small earlyflowering ruderals (R/CR-selected), and (2) largerleaved competitors $(\mathrm{C} / \mathrm{CR})$ flowering later as dominant graminoids attained maximum height. These orchids, and other subordinate species in the community, exhibited random spatial distributions amongst dominant graminoids that exhibited a high degree of spatial aggregation and similar, but non-identical, stresstolerator (S) strategies. The reproductive phenology of meadow orchids is an intimate component of their CSR strategies, and appears to promote coexistence by allowing segregation between temporal niches and the exploitation of opportunities between clumps of dominant species. Only for closely related species with identical CSR strategies, such as Ophrys benacensis and Ophrys sphegodes, could specific floral differences alone explain coexistence.

Keywords Biodiversity - Coexistence ·

Community assembly · Plant functional type . Species richness - Universal adaptive strategy theory

\section{Introduction}

At the global scale, the orchid family (Orchidaceae) represents one of the most extensive adaptive radiations in the plant kingdom, due to evolutionary divergence in life-form, photosynthetic pathways 
(Silvera et al. 2005), mycorrhizal associations (Arditti 1992; Otero et al. 2002; Rasmussen 2002) and reproductive characteristics and thus pollinator identity (Dressler 1981; Benzing and Atwood 1984; Soliva and Widmer 2003; Scopece et al. 2007). However, at the local scale a number of different orchid species may coexist despite exhibiting apparently similar growth requirements and persistence on the same substrate often literally side-by-side, for example in species-rich European dry calcareous grasslands. Furthermore, some of these species may be locally common whilst others are extremely rare even in apparently ideal habitat. Understanding how these species coexist, within the context of the wider plant community, could allow optimization of conservation measures targeted at particularly rare species (Pierce et al. 2006).

The most evident differences between grassland orchids are floral differences. Can these explain coexistence? Co-occurring orchid species are known to exhibit floral/pollinator differences that are especially important for the separation and coexistence of recently diverged species (Waterman et al. 2011; see also Waser 1983). In general, pollinators are considered a resource for which plants compete (Rathcke 1983; Pierce et al. 2007) and the differential exploitation of resources (resource partitioning) is essential for niche segregation and thus coexistence (Martin 1996). Pollinator resource partitioning is hypothesized to play a key role in the assembly of flowering plant communities (e.g. Armbruster et al. 1994), and specifically the divergence of floral traits has been implicated in the speciation and subsequent coexistence of South African oil-secreting orchids (subtribe Coryciinae; Waterman et al. 2011).

However, although floral/pollination differences are important during speciation less closely related orchid species tend to form pollination guilds in which pollinators are shared, and pollinator resource partitioning is evidently less important to coexistence (Waterman et al. 2011). Even species that are extremely specialized, such as the European bee orchids (Ophrys spp.), may share multiple pollinating species (Kullenberg 1950). Worldwide approximately a third of all orchid species are dependent on deceptive pollination mechanisms, meaning that they rely on sharing pollinators with non-orchidaceous species that provide nectar and actually support pollinator activity (Cozzolino and Widmer 2005). Thus although orchid pollination mechanisms may be intricate and idiosyncratic the pollinators themselves are often shared with other orchid and non-orchid species. Thus variety in floral characteristics alone is unlikely to explain coexistence.

Pollinator and mycorrhizal mutualisms are of undoubted relevance to orchid evolution and ecology, but by focusing on interactions with other organisms the inherent differences in vegetative traits of the orchids themselves have received little attention in the context of orchid coexistence. For instance, light availability for photosynthesis is known to be one of the principal factors structuring terrestrial orchid populations, and depends on the characteristics of surrounding plants within the community and ultimately vegetation management. In Europe many orchid species require high light intensities at ground level associated with mown or grazed habitats and are thus restricted to anthropogenic grasslands, and when they become shaded by encroaching woody species the orchids lack sufficient energy to flower and fruit (Dorland and Willems 2006; Jacquemyn et al. 2008). Grazing and the removal of woody species encourage orchid recruitment (Hutchings et al. 1998), and cutting is known to increase calcareous grassland species richness in general (e.g. Pärtel et al. 1998). Thus, the traits of orchids and surrounding plant species, such as leaf size, canopy height and ability to intercept light, are likely to play a key role in determining how orchids interact with immediate neighbours.

Competition for resources such as light and mineral nutrients has traditionally formed a focus of plant coexistence studies (e.g. Tilman 1988; Reynolds et al. 1997; Grime 2001; Fargione and Tilman 2006; Craine 2009). Particular importance is given to the plant traits that regulate the acquisition of resources used for growth. Apart from leaf size, 'economics' traits form a major axis of variability in vascular plant phenotypes globally known as the "worldwide leaf economics spectrum' (Wright et al. 2004). This spectrum reflects a gradient of acquisitive to conservative resource investment strategies evident in resource-rich to resource-poor habitats, and consistently emerges in multivariate analyses of plant traits (Díaz et al. 2004; Cerabolini et al. 2010; Frenette-Dussault et al. 2012; Freschet et al. 2012; Pierce et al. 2013). At the 'acquisitive' end of this spectrum are leaves with high specific leaf area (i.e. thin leaves with little mass per unit area) as opposed to 'conservative' leaves with 
high leaf dry matter content. In the particular case of orchids differences in leaf size and economics could potentially have a fundamental role in allowing different species to coexist and persist within the wider community.

Does such leaf trait variation exist between cooccurring orchids? Does variation in orchid leaf traits reflect variation in reproductive traits, as part of the primary life-history strategy? Primary strategies are essentially suites of traits that impact on key functions allowing survival, and involve the investment of photosynthates and mineral nutrients in three principal activities: further growth, the maintenance and protection of metabolic processes, or reproduction (Grime and Pierce 2012). Strategies thus represent a three-way investment trade-off between traits facilitating these competing functions: a trade-off that has been recorded repeatedly in large scale studies of wild plants (Díaz et al. 2004; Cerabolini et al. 2010; Frenette-Dussault et al. 2012; Pierce et al. 2013). These three principal extremes of adaptive specialization are predicted by Grime's (2001) competitor, stress-tolerator, ruderal (CSR) plant strategy theory and its successor, universal adaptive strategy theory (Grime and Pierce 2012), in which C-selected 'competitors' maximize growth by using large physical size (large leaves and root systems, tall canopies) to acquire resources and dominate stable, resource-rich niches. S-selected 'stress-tolerators' grow in abiotically extreme, variable habitats, hoarding resources for later use to tolerate periods when metabolic processes operate sub-optimally and productivity is limited. R-selected 'ruderals' grow extremely rapidly to support early and extensive reproduction in relatively resource-rich niches that periodically experience disturbance (biomass destruction). The R- and S-selected extremes have been shown to be correlated directly with 'acquisitive' and 'conservative' leaf economics trait values, and large-leaved competitors are evident only at the mid-point of the leaf economics spectrum (Cerabolini et al. 2010). Thus a CSR classification method has recently been produced that uses a combination of leaf economics and leaf area measurements to assign species a precise position within the CSR triangle (Pierce et al. 2013).

Here we investigate the hypothesis that the coexistence of orchid species in a dry calcareous grassland is associated with heterogeneity in CSR strategies determined from leaf economics and size traits, and that differences in flowering and fruiting phenology reflect variation in these strategies. Orchid co-existence is additionally set in the context of the CSR strategies apparent in the wider plant community. Thus the present study quantifies and compares the CSR strategies, phenology, and relative abundances and spatial distribution of co-existing orchidaceous and non-orchidaceous species in a xeric sand grassland.

\section{Methods}

Field site

'Prato Olivino' (translated as the Olive Lawn) is a 1.6 ha xeric sand calcareous grassland (consistent with EU Habitats Directive habitat number 6210*, European Environment Acency habitat E1.262, CORINE Biotope 34.33) on shallow, slightly alkaline soil overlying limestone $(\mathrm{pH} 7.3$ in the upper horizon; $\mathrm{S}$. Pierce unpublished data). This site was chosen as a particularly orchid-rich relict site including a range of species that are not found in smaller grassland fragments persisting in the region (Guidi 2011). The Olive Lawn is found at low altitude $(260 \mathrm{~m}$ asl) at the foot of the eastern flank of Monte Barro (Mount Barro) near to Lake Pescate, an offshoot of Lake Como (the general location is $\mathrm{N} 45^{\circ} 49^{\prime}$, E $09^{\circ} 23^{\prime}$, but orchid poaching is a problem in the area and so the precise location shall not be revealed here). It is managed by mowing using traditional hand tools in the early summer (early to mid July; Fig. S1), and no fertilizer is applied: a management regime that has been maintained since before living memory (Valsecchi, S. [land-owner and farmer], personal communication). Three small olive groves are present, but mowing is mainly conducted to provide winter hay for domestic livestock and has therefore created extensive areas of open grassland free of olive trees (Fig. S1).

Functional trait measurement and CSR classification

CSR classification was conducted for orchid species following the method of Pierce et al. (2013). Specifically, one entire, undamaged, distal, fully-expanded leaf was harvested from each of ten individuals (where possible: for the extremely rare species Ophrys 
benacensis and Serapias vomeracea this was limited to four replicates, for Neotinea ustulata only six individuals were evident at the site). Plant material was placed on wetted tissue paper, wrapped in aluminium foil and stored at $4{ }^{\circ} \mathrm{C}$ overnight prior to determination of saturated (turgid) leaf fresh weight (LFW; Cornelissen et al. 2003; Cerabolini et al. 2010). Single-sided leaf area was then measured by performing a digital scan of each leaf and using the free areadetermination software leaf area measurement (LAM v1.3 by Andrew Askew), available from: www. nucleodiversus.org/uploads/file/leafarea.zip

This was calibrated using graph-paper squares of known area $\left(50 \mathrm{~mm}^{2}\right)$. Leaf dry weight (LDW) was then determined following drying for $24 \mathrm{~h}$ at $85^{\circ} \mathrm{C}$, and parameters such as SLA (i.e. leaf area (LA) divided by LDW) were calculated (Pierce et al. 2007). Leaf dry matter content (LDMC) was calculated as the proportion of LFW accounted for by LDW.

Values of leaf area, SLA and LDMC were then inserted into the 'CSR Triangulator Vascular Plants' tool of Pierce et al. (2013) to calculate the mean CSR strategy for each species (the index of C-selection is influenced mainly by leaf area values, the index of S-selection by LDMC, and R-selection by SLA, although the final CSR strategy is weighted to take into account the trade-off between these competing leaf functions). This is an automatic CSR strategy calculator spreadsheet in Microsoft Excel format calibrated using an ecologically diverse range of herbaceous and woody angiosperm, gymnosperm and pteridophyte species, downloadable from: http:// onlinelibrary.wiley.com/doi/10.1111/1365-2435.12095/ suppinfo

For non-orchidaceous species, mean leaf trait values and canopy height data for local populations at Parco Monte Barro were already available in the Flora d'Italia Functional Traits Hoard (FIFTH database; Cerabolini et al. 2010; these data are also available from the global TRY database at www.trydb.org), and were inserted into the CSR Triangulator VP tool to calculate mean CSR strategies for each species. However, eleven non-orchidaceous species found at the Olive Lawn were not present in the FIFTH database, and CSR strategies were calculated from leaf material collected in the field in the same manner as described above for the orchid species. Nomenclature follows Pignatti (1982) and, for the orchids, GIROS (2009), and all author names are included in the database and CSR calculation spreadsheet of Table S1 (Microsoft Excel format).

Phenology

Orchid reproductive phenology was determined for each species as the date of first flowering, the date at which the first fruits were apparent, and the dihiscence of fruits (i.e. end of fruiting). Contemporaneously, canopy height (maximum height above the ground of the most distal leaf surface) was determined over time for graminoid species as a general indicator of plant growth and the seasonal increase of the vegetation.

Species relative abundance

Transects were placed where extensive areas of relatively uniform vegetation were apparent, avoiding areas underneath olive trees, near rocky outcrops and the edge of the site (the site is surrounded by oak/ hornbeam woodland). A total of 16 transects were conducted, each $5 \mathrm{~m}$ in length and orientated in a north-south direction, with all transects on flat areas of land. Along each transect, the identity of species rooted at each centimetre interval was recorded (i.e. a total of 8,000 points across all transects). This large number of sample points across replicate transects was necessary to provide confidence in the spatial distributions of species and relative abundances for small plants in a highly species rich, heterogeneous biotic context. Species relative abundance was calculated for each transect, with species categorized as 'dominant' or 'subordinate' if they represented more or less, respectively, than $10 \%$ of the individuals along the transect, following Grime (1998).

Spatial distribution of species

The variance to mean ratio, or index of aggregation (I), was calculated for each species using the following equation (Elliott 1993):

$I=\frac{\sum(x-\bar{x})^{2}}{\bar{x}(n-1)}$,

where $x$ is the number of individuals in any given 25$\mathrm{cm}$ portion (or 'bin') of the transect, $\bar{x}$ is the mean number of individuals per bin, and $n$ is the number of bins. A value of $I=1$ indicates a random dispersion, 
with increasing values indicating increasingly aggregated dispersion along the transect. $I$ indicates the extent to which the sample (real) variance differs from the theoretical (potential) variance but does not indicate significance. To gauge significance, the normalized variable $d$ was calculated thus:

$d=\sqrt{2 \chi^{2}}-\sqrt{2 v-1}$,

where $v$ is the number of degrees of freedom (in practical terms, the number of bins-1), and

$\chi^{2}=\frac{s^{2}(n-1)}{\bar{x}}$,

where $s^{2}$ is the sample variance. If $d$ is $>1.96$, then the population distribution is significantly contagious (i.e. an aggregated dispersion) at the $P \leq 0.05$ level. Conversely, $d<-1.96$ indicates a significantly regular distribution, at the $P \leq 0.05$ level, and lack of significance indicates a random distribution (Elliott 1993). Thus, $I$ and $d$ are used together: the former describing the relative dispersion along the transect and the latter indicates the reliability of $I$ (Pierce et al. 2006).

\section{Results}

Four orchid species (Anacamptis morio, Anacamptis pyramidalis, Neotinea tridentata and Ophrys sphegodes subsp. atrata) were relatively common at the site and were detected along the transects, although three additional species ( $N$. ustulata, O. benacensis and $S$. vomeracea) were observed to be in flower at the site but were not detected along the transects (i.e. a total of seven orchid species were present at the site). A total of 76 herbaceous angiosperm species were recorded along the transects (for details see Table S1), eleven of which were Poaceae. The prevalence of the graminoids Brachypodium rupestre, Festuca stricta subsp. sulcata, Carex caryophyllea and Bromus erectus, the presence of characteristic species (e.g. Anthyllis vulneraria, Carex caryophyllea, Centaurea scabiosa, Hippocrepis comosa, Leontodon hispidus, Medicago sativa, Primula veris, Sanguisorba minor) and the number and identity of orchid species at the site were consistent with an orchid-rich Xerobromion erecti plant community.

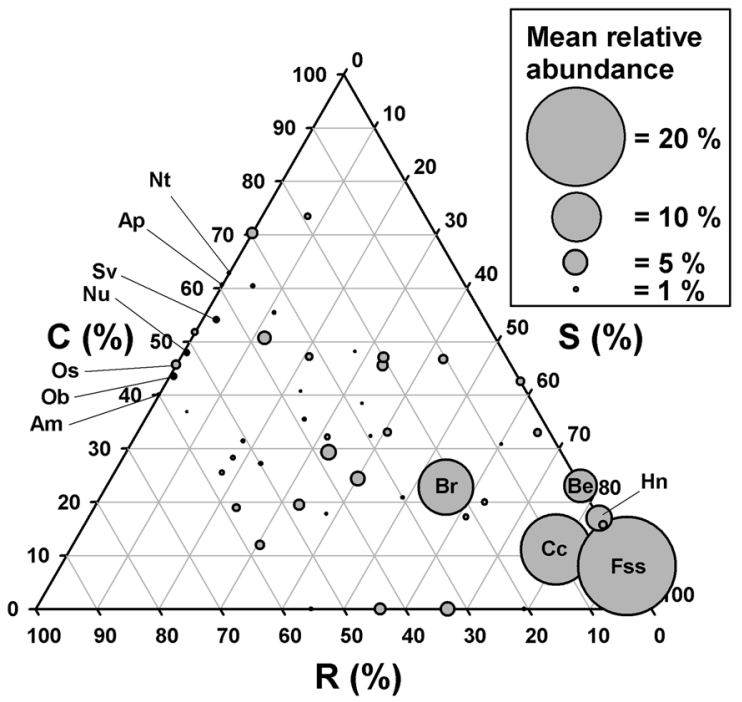

Fig. 1 A CSR triangle contrasting the life-history strategies and mean relative abundances of orchid species and nonorchidaceous species coexisting in dry calcareous grassland at the Olive Lawn, Pescate (Lecco), northern Italy. Mean relative abundance was calculated from 16 replicate $5 \mathrm{~m}$ transects, and the circumference of points on the plot is directly proportional to relative abundance. Highlighted species are either orchids (Am, A. morio; Ap, A. pyramidalis; Nt, N. tridentata; Nu, N. ustulata; Os, O. sphegodes; Sv, S. vomeracea) or relatively abundant species ( $>5 \%$ of the plant community (Be, B. erectus; $\mathrm{Br}, B$. rupestre; Cc, C. caryophyllea; Fss, F. stricta subsp. sulcata; Hn, H. nummularium). Dominant species are considered to be those exhibiting $>10 \%$ relative abundance, following Grime (1998). Note that the orchids $\mathrm{Nu}, \mathrm{Ob}$ and $\mathrm{Sv}$ were present at the study site in extremely small numbers of individuals, and were not detected along the transects: relative abundance could not be calculated, and these species have been added here to allow comparison of CSR strategies between all orchids

The mean CSR strategies of orchids (alongside other non-orchidaceous species) across all transects are shown in relation to species relative abundance in the CSR triangle presented in Fig. 1. (Details of all separate transects are available in Fig. S2). The relatively common orchids present along the transects included A. morio (C:S:R = 40:0:60 \%), A. pyramidalis (61:0:39\%), N. tridentata (63:0:37\%) and $O$. sphegodes (46:0:54\%). The orchid species that were observed at the site but were locally rare and not detected along the transects exhibited C:S:R values as follows: $N$. ustulata, 49:0:51 \% $(n=6)$; O. benacensis, $42: 0: 58 \%(n=4) ; S$. vomeracea, $54: 3: 43 \%$ $(n=4)$. Note that as these latter species were not found along transects, they have been added manually 


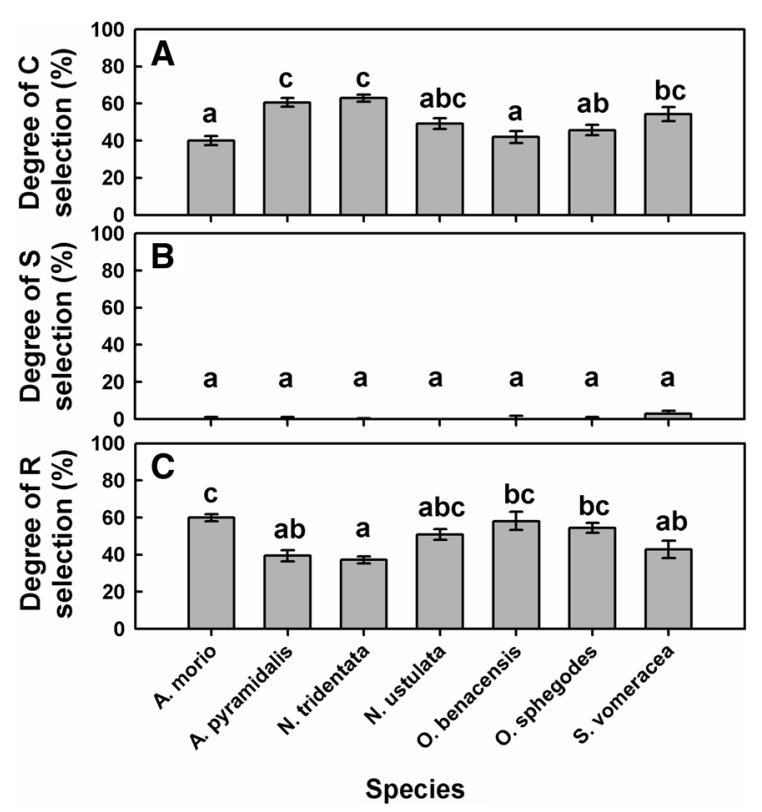

Fig. 2 Statistical differences in the degree of C-, S-, and R-selection measured via CSR classification (using leaf economics and size traits) for seven orchid species coexisting in xeric sand calcareous grassland at the Olive Lawn, near Lecco, Italy. Different letters indicate significant differences at the $P \leq 0.05$ level as determined by ANOVA and Tukey's multiple comparison post hoc test (in panel $A, F$ ratio $=10.167$, $\mathrm{df}=6, P=0.000 ;$ in panel $C, F$ ratio $=7.263$, $\mathrm{df}=6$, $P=0.000)$. Percentage data were arcsine transformed prior to ANOVA

to Fig. 1 to allow comparison with the other orchid species.

The CSR strategies and relative abundances of the non-orchidaceous species demonstrate that the S-selected stress-tolerators B. rupestre, C. caryophyl$l e a$, and F. stricta dominated (Fig. 1). Note that Fig. S3 shows the descriptive statistics for relative abundance data presented in the form of a classic rank/ abundance curve or logseries. Additionally, B. erectus and $H$. nummularium were also strongly S-selected, although each was ordinated in a slightly different region of the CSR triangle (Fig. 1). Non-orchidaceous subordinate species ranged from the relatively C-selected Plantago lanceolata (tertiary CSR strategy $=\mathrm{C} / \mathrm{CSR} ; \quad$ measured $\mathrm{C}: \mathrm{S}: \mathrm{R}$ values = 73:7:19\%), strongly S-selected (Teucrium chamaedrys; 16:84:0 \%), and R/CSR selected Leucanthemum vulgare $(27: 23: 50 \%)$.

Figure 2 provides a statistical comparison of the CSR strategies of all seven orchid species. A. morio,
$O$. benacensis and $O$. sphegodes exhibited a significantly (at the $P \leq 0.05$ level) higher degree of R-selection with respect to other orchid species present at the site, and A. pyramidalis and $N$. tridentata a significantly higher degree of C-selection (Fig. 2; e.g. A. pyramidalis had moderately large leaves of $1194 \pm 147.9 \mathrm{~mm}^{2}$; Table S1). N. ustulata and $S$. vomeracea had intermediate, CR-selected strategies (Fig. 2).

Figure 3 shows the phenology of orchid flowering and fruiting in conjunction with the extension of canopy height for prevalent graminoids at the Olive Lawn. Snow was present at the site until mid March in 2013, and 3 days after the snow melted $O$. sphegodes initiated flowering. This was followed over the course of the following month and a half by the growth in height of the graminoids (Fig. 3) and the flowering of A. morio and $O$. benacensis. When the tallest graminoids attained maximum canopy height, at the start of May, O. sphegodes and A. morio started fruiting. At this point $A$. pyramidalis, $N$. tridentata, N. ustulata, and slightly later, S. vomeracea started flowering. Vegetation was mown to a mean height of $7 \mathrm{~cm}(n=10)$ by the landowner at the start of July. By the time of mowing, the early-flowering orchid species had all completed fruiting (i.e. seed capsules were dehiscent), whereas the late-flowering orchid species were still in the fruiting phase, with $A$. pyramidalis at the start of fruiting (Fig. 3). Although phenology was only recorded during 2013, the corresponding author has collected orchid seed for germination studies from this site each year for the previous 9 years, and the relative flowering and fruiting times of species recorded for 2013 were in agreement with prior experience: $O$. sphegodes (the Early Spider Orchid) is consistently the first species to flower immediately after snowmelt, followed by the remaining species in the order described above, with mowing consistently occurring in July.

Figure 4 shows a statistically significant positive linear correlation between spatial aggregation $(I)$ and species relative abundance (i.e. $R^{2}=0.736$, ANOVA: $f=148.0462, \quad P<0.0001)$. Dominant graminoid species of $>10 \%$ relative abundance $(B$. erectus, $B$. rupestre, $C$. caryophyllea and $F$. stricta) all exhibited highly aggregated spatial distributions (i.e. local populations consisted of compact genets). Subordinate 
Fig. 3 Phenology of orchid flowering and fruiting in correspondence with the extension of canopy height for graminoids in xeric sand calcareous grassland at the Olive Lawn, Pescate (Lecco), northern Italy

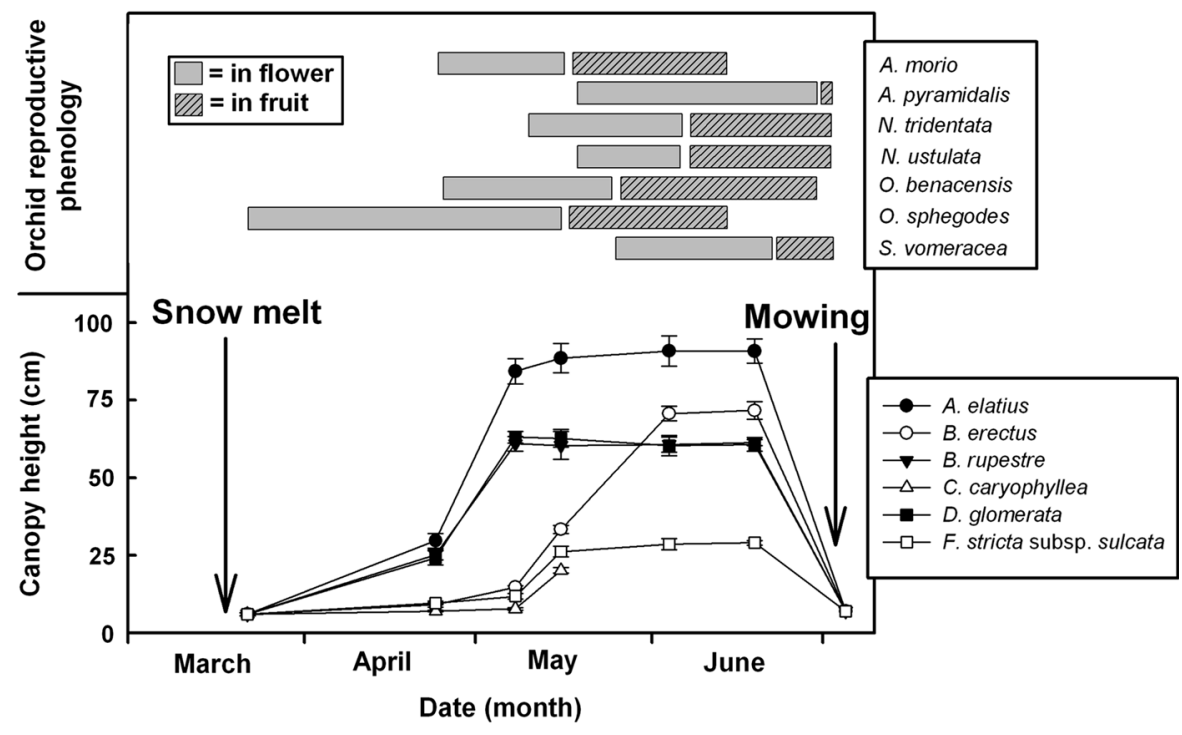

Discussion

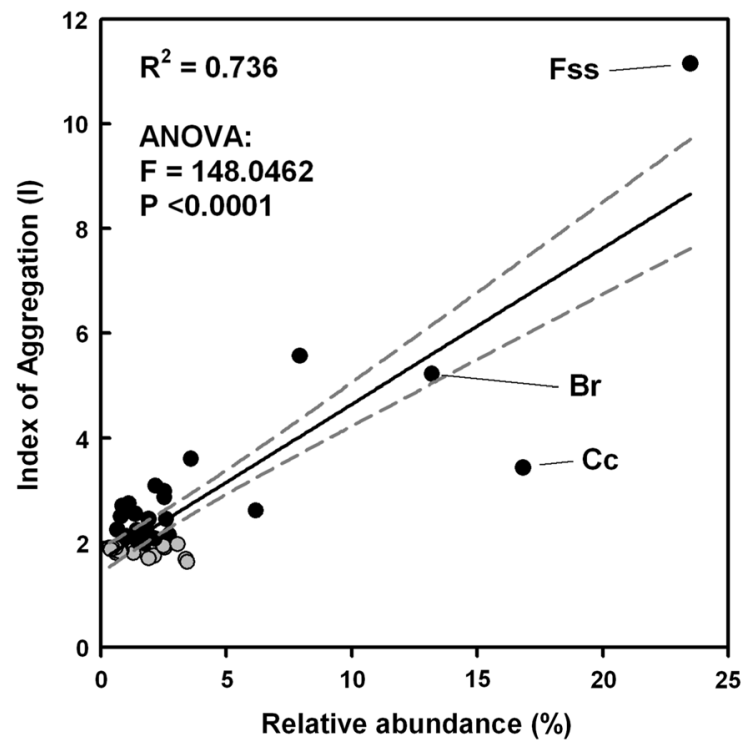

Fig. 4 The relationship between the spatial aggregation $(I)$ of each species and relative abundance. Grey-filled circles denote species for which aggregation was not significant at the $P \leq 0.05$ level (i.e. $d<1.96$ ), and black filled circles denote significant aggregation $(P \leq 0.05$ and $d>1.96)$. Dashed lines represent $95 \%$ confidence intervals. Dominant species $(>10 \%)$ are indicated: $\mathrm{Br}, B$. rupestre; Cc, C. caryophyllea; Fss, F. stricta subsp. sulcata

species either exhibited a low but significant degree of spatial aggregation or aggregation was not significant (i.e. random spatial distributions along the transects; Fig. 4).
The seven orchid species present at the Olive Lawn were essentially competitive ruderals (CR-selected), but species exhibited a spectrum of variation around this strategy, and two functional extremes were evident. A. morio, O. benacensis, and $O$. sphegodes were relatively R-selected, having small leaves with high specific leaf area, and flowered early in the season before the dominant graminoids attained maximum canopy height. For these species, fruiting was complete before the vegetation was mown (Fig. 3). Additionally, these are all species that produce small numbers of flowers (GIROS 2009). Thus they appear to use a low-risk approach that guarantees the production of smaller numbers of fruits before shading by the rest of the plant community and subsequent mowing impact the vegetation. This is consistent with, for example, the population dynamics of $O$. sphegodes, which has a short lifespan and populations persist due to recruitment from seed (Hutchings 1987). Despite persisting for several years plants are in many ways 'analogous to winter annual plants' (Hutchings 1987). Early flowering has also been recorded in British populations of $A$. morio and interpreted as an adaptation to avoid summer heat and drought, using essentially a Mediterranean life cycle (Wells et al. 1998). At the opposite extreme A. pyramidalis and $N$. tridentata had large leaves and intermediate leaf 
economic trait values and flowered later when the vegetation had reached maximum height. These are both relatively tall species with large inflorescences, each inflorescence bearing numerous flowers and fruits above the herbaceous canopy (GIROS 2009). Fruiting of these orchids was interrupted by mowing (Fig. 3). These species thus appear to employ a higher risk approach in which they do not necessarily complete the life cycle but, when successful, can invest more resources in greater numbers of fruits. Species such as $N$. ustulata exhibited an intermediate strategy between these extremes along what was essentially a spectrum of plant CSR strategies.

It is clear that flowering and fruiting phenology is important for grassland orchid species, but also that reproductive phenology is intimately linked to the CSR strategy of the species. Cerabolini et al. (2010) found that for a broad range of herbaceous species, the degree of R-selection determined from leaf economics traits was correlated with earlier flowering and a longer flowering period, and stress-tolerators start flowering later in the year (although these were not coexisting species). Thus reproductive timing is an integral component of the CSR strategy, and CSR strategy variation is a characteristic of coexisting orchid species. However, CSR strategies are unlikely to reveal the whole story. For example, the bee orchids $O$. sphegodes and $O$. benacensis both had essentially the same CSR strategy (Fig. 1). The former species is recognised as common in northern Italy (GIROS 2009) and was indeed the most common orchid found along the transects in the present study, whilst the latter is an extremely rare stenoendemic that was not found along the transects because only four individuals were present at the entire study site. Thus understanding the primary CSR strategy will not shed much light on why one species is rare and another common in the same habitat, which is a fundamental concern for species conservation. In this particular case, the two species are extremely closely related, to the extent that it has been suggested that $O$. benacensis could be a natural hybrid between $O$. sphegodes and $O$. bertolonii, differing mainly in the species of solitary bee that $O$. benacensis exploits as its typical pollinator (Pedersen and Faurholdt 2007). Cases of speciation via hybridization, floral character displacement, and pollinator shift have been recorded for other species of Ophrys (Schlüter et al. 2009), and are dependent on very specific traits such as the range of molecules involved in creating floral scents (Vereecken et al. 2010). Thus extremely subtle differences between small numbers of traits not entrained in the CSR model, particularly floral traits and the identities of pollinators, are of importance to coexistence in specific cases of very closely related orchid species. Variation in orchid CSR strategies appears to be associated with coexistence, but in specific cases in which the CSR strategy is identical floral characters differ and form a secondary level of trait variability that can explain coexistence (e.g. O. sphegodes and O. benacensis).

A theoretical explanation for this can be found in the twin-filter model of community assembly (Grime and Pierce 2012), in which two controlling processes or 'filters' regulate species admission into plant communities from the local species pool: a filter operating on a day-to-day basis to select the general life history strategy (the 'Competition-Stress-Disturbance' or 'CSD' filter) and a subsequent filter selecting against traits that are of intermittent importance to the persistence of populations, including reproductive traits (the 'proximal filter'). Thus CSR strategies determine the subset of the local species pool that can survive locally, but single traits or small subsets of traits that operate only periodically have a subsequent role in fine-tuning coexistence. Co-occurring meadow orchids, due to their apparently similar lifestyles and growth mode, have previously been suggested as an example of species that rely on differences in proximal filter traits for coexistence, in particular floral form and flowering phenology (Grime and Pierce 2012). However, the present study demonstrates that the effects of these proximal traits are likely to be more subtle and perhaps of lesser importance to community assembly than previously thought. Thus whilst CSR strategies are useful for providing a general overview of the plant community, understanding particular cases, such as why $O$. benacensis is rare but $O$. sphegodes is common, is unfortunately only likely to be achieved by close examination of species' ecology on a case-by-case basis. In this case the rarity of $O$. benacensis may depend more on factors such as the limited arrival of diaspores for a species that has a limited geographic distribution (sensu Pärtel et al. 1998), which is good news for the conservation of this species as reintroduced plants will be well adapted to the habitat.

With regard to the entire plant community at the Olive Lawn dominance was attained by stress- 
tolerator graminoids with aggregated (clumped) distributions (Fig. 4). However, dominant species all exhibited slightly different CSR strategies from one another, suggesting that character displacement (i.e. functional differences in suites of characters) and niche segregation operate to promote co-dominance at this site. Subordinate species exhibited a much broader range of strategies and were either randomly dispersed or only slightly aggregated, suggesting that they occupied the physical spaces between genets of dominant species. Fine-scale environmental heterogeneity is generally accepted as significant to coexistence in grassland communities (Fitter 1982; Reynolds et al. 1997; Fridley et al. 2011), and thus the observation in the present study of heterogeneity in primary strategies provides a potential link between the adaptations of each species and their position within a mosaic of potential microsites and the plant community.

What is the nature of these microsites? It has been suggested that different CSR strategies may coexist mainly due to fine-scale variability in microsite soil depth and the differential capacity of strategies to exploit soil resources (Fridley et al. 2011). In the case of the Olive Lawn this possibility can be ruled out as soil penetrometer readings directly under C/CSR, Sand R-selected species suggest a substrate of uniform depth $(40.3 \pm 2.48 \mathrm{~cm})$, with no significant difference in depth under contrasting plant strategies $(n=40$; Fig. S4). As light availability is a key factor structuring orchid habitats and affecting orchid populations (Dorland and Willems 2006; Jacquemyn et al. 2008), we suggest that the coexistence of species differing in leaf size and leaf economics in calcareous grassland may depend more on light availability and the physical architecture and heterogeneity of the canopy. Indeed, the orchids exhibited canopy heights of between $43 \mathrm{~mm}$ (O. benacensis) and $172 \mathrm{~mm}$ ( $N$. tridentata; Supplementary Table S1), whereas one of the dominant species (B. rupestre) attained $613 \mathrm{~mm}$, and some subordinates, such as Arrhenatherum elatius, were as tall as $910 \mathrm{~mm}$ (Fig. 3). Leaves of O. benacensis exhibited only $30 \%$ of the area of $N$. tridentata leaves (Table S1). Thus the smaller, relatively R-selected orchids are found at the lowest level in the canopy (but flower quickly to avoid shading) whereas the relatively $\mathrm{C}$-selected orchids are able to compete at a higher level. Spatial and temporal gradients in light availability could account for the coexistence of species with different CSR strategies.

\section{Conclusions}

Grassland orchids at the Olive Lawn exhibit suites of co-varying vegetative and reproductive traits, embodied in CSR strategies, allowing coexistence in subordinate circumstances amongst clumps of dominant species. This concept of subordinance and contrasting life-history strategies as positive factors allowing survival and promoting species richness is at direct odds with models of plant coexistence that rely solely on competition for resources between similar species, in which local resource monopoly and dominance are seen as the only route to survival (e.g. the resourceratio hypothesis; Tilman 1988). Species-rich plant communities are not battlegrounds where similarly armed combatants wage war, but are more akin to city centres in which large department stores dominate the local retail economy but smaller specialist shops can also survive because they do business in a way that is complementary, rather than antagonistic, to the larger retailers. Grassland orchids are the chocolatiers, guitar shops and numismatic shops tucked away among the back alleys.

Acknowledgments We thank Salvatore Valsecchi (the owner of the fieldsite) the Native Flora Centre of the Lombardy Region (CFA) and Parco Monte Barro (acting on behalf of the Lombardy Region) for permission to work at the site and collect plant material, and for access to the equipment and laboratory at Monte Barro where leaf area and weight were determined. Pierfranco Arrigoni originally made the authors aware of the presence of the orchids at the site.

\section{References}

Arditti J (1992) Fundamentals of orchid biology. Wiley, New York

Armbruster WS, Edwards ME, Debevec EM (1994) Floral character displacement generates assemblage structure of Western Australian triggerplants (Stylidium). Ecology 75:315-329

Benzing DH, Atwood JT (1984) Orchidaceae: ancestral habitats and current status in forest canopies. Syst Bot 9:155-165

Cerabolini BEL, Brusa G, Ceriani RM, De Andreis R, Luzzaro A, Pierce S (2010) Can CSR classification be generally applied outside Britain? Plant Ecol 210:53-261 
Cornelissen JHC, Lavorel S, Garnier E, Diaz S, Buchmann N et al (2003) A handbook of protocols for standardised and easy measurement of plant functional traits worldwide. Aust J Bot 51:335-380

Cozzolino S, Widmer A (2005) Orchid diversity: an evolutionary consequence of deception? Trends Ecol Evol 20(9):487-494

Craine JM (2009) Resource strategies of wild plants. Princeton University Press, Princeton

Díaz S, Hodgson JG, Thompson K, Cabido M, Cornelissen JHC et al (2004) The plant traits that drive ecosystems: evidence from three continents. J Veg Sci 15:295-304

Dorland E, Willems JH (2006) High light availability alleviates the costs of reproduction in Ophrys insectifera (Orchidaceae). J Europäischer Orchideen 38(2):501-518

Dressler RL (1981) The orchids. Natural history and classification. Harvard University Press, Cambridge

Elliott JM (1993) Some methods for the statistical analysis of samples of benthic invertebrates. Scientific publication 25 . Freshwater Biological Association, Ambleside

Fargione J, Tilman T (2006) Plant species traits and capacity for re source reduction predict yield and abundance under competition in nitrogen-limited grassland. Funct Ecol 20:533-540

Fitter AH (1982) Influence of soil heterogeneity on the coexistence of grassland species. J Ecol 70:139-148

Frenette-Dussault C, Shipley B, Léger J-F, Meziane D, Hingrat Y (2012) Functional structure of an arid steppe plant community reveals similarities with Grime's C-S-R theory. J Veg Sci 23:208-222

Freschet GT, Aerts R, Cornelissen HC (2012) A plant economics spectrum of litter decomposability. Funct Ecol 26:56-65

Fridley JD, Grime JP, Askew AP, Moser B, Stevens CJ (2011) Soil heterogeneity buffers community response to climate change in species-rich grassland. Glob Change Biol 17:2002-2011

GIROS (Italian Group for Research on Spontaneous Orchids) (2009) Orchidee d'Italia (Orchids of Italy). Il Castello, Cornaredo (in Italian)

Grime JP (1998) Benefits of plant diversity to ecosystems: immediate, filter and founder effects. J Ecol 86:901-910

Grime JP (2001) Plant strategies, vegetation processes and ecosystem properties, 2nd edn. Wiley, Chichester, p 417

Grime JP, Pierce S (2012) The evolutionary strategies that shape ecosystems. Wiley-Blackwell, Chichester

Guidi V (2011) Study of the biodiversity of native orchids in the province of Lecco. Unpublished BSc thesis, University of Milan Bicocca, Milan, p 81

Hutchings MJ (1987) The population biology of the early spider orchid, Ophrys sphegodes Mill. I. Demographic study from 1975 to 1984. J Ecol 75(3):711-727

Hutchings MJ, Mendoza A, Havers W (1998) Demographic properties of an outlier population of Orchis militaris L. (Orchidaceae) in England. Bot J Linn Soc 126:95-107

Jacquemyn H, Brys R, Honnay O, Hermy M (2008) Effects of coppicing on demographic structure, fruit and seed set in Orchis mascula. Basic Appl Ecol 9:392-400

Kullenberg B (1950) Investigations on the pollination of Ophrys species. Oikos 2(1):1-19

Martin EM (1996) Fitness costs of resource overlap among coexisting bird species. Nature 380:338-340
Otero JP, Ackerman JD, Bayman P (2002) Diversity and host specificity of endophytic Rhizoctonia-like fungi from tropical orchids. Am J Bot 89(11):1852-1858

Pärtel M, Kalamees R, Zobel M, Rosén E (1998) Restoration of species-rich limestone grassland communities from overgrown land: the importance of propagule availability. Ecol Eng 10:275-286

Pedersen HÆ, Faurholdt M (2007) Ophrys: the bee orchids of Europe. Kew Publishing, London

Pierce S, Ceriani RM, Villa M, Cerabolini B (2006) Quantifying relative extinction risks and targeting intervention for the orchid flora of a natural park in the European pre-alps. Conserv Biol 20(6):1804-1810

Pierce S, Luzzaro A, Caccianiga M, Ceriani RM, Cerabolini B (2007) Disturbance is the principal $\alpha$-scale filter determining niche differentiation, coexistence and biodiversity in an alpine community. J Ecol 95:698-706

Pierce S, Brusa G, Vagge I, Cerabolini BEL (2013) Allocating CSR plant functional types: the use of leaf economics and size traits to classify woody and herbaceous vascular plants. Funct Ecol 27(4):1002-1010

Pignatti S (1982) Flora d'Italia. Edagricole, Bologna

Rasmussen HN (2002) Recent developments in the study of orchid mycorrhiza. Plant Soil 244:149-163

Rathcke BJ (1983) Competition and facilitation among plants for pollination. In: Real L (ed) Pollination Biology. Academic Press, New York, pp 305-329

Reynolds HL, Hungate BA, Chapin FS, D'Antonio CM (1997) Soil heterogeneity and plant competition in an annual grassland. Ecology 78:2076-2090

Schlüter PM, Ruas PM, Kohl G, Ruas CF, Stuessy TF, Paulus HF (2009) Genetic patterns and pollination in Ophrys iricolor and $O$. mesaritica (Orchidaceae): sympatric evolution by pollinator shift. Bot J Linn Soc 159: 583-598

Scopece G, Musacchio A, Widmer A, Cozzolino S (2007) Patterns of reproductive isolation in Mediterranean deceptive orchids. Evolution 61(11):2623-2642

Silvera K, Santiago LS, Winter K (2005) Distribution of crassulacean acid metabolism in orchids of Panama: evidence of selection for weak and strong modes. Funct Plant Biol 32:397-407

Soliva M, Widmer A (2003) Gene flow across species boundaries in sympatric, sexually deceptive Ophrys (Orchidaceae) species. Evolution 57(10):2252-2261

Tilman D (1988) Plant Strategies and the Dynamics and Structure of Plant Communities. Princeton University Press, Princeton

Vereecken NJ, Cozzolino S, Schiestl FP (2010) Hybrid floral scent novelty drives pollinator shift in sexually deceptive orchids. BMC Evol Biol 10:103

Waser NM (1983) Competition for pollination and floral characters differences among sympatric species: a review of evidence. In: Jones DE, Little RJ (eds) Handbook of experimental pollination biology. Van Nostrand Reinhold, New York, pp 277-293

Waterman RT, Bidartondo MI, Stofberg J, Combs JK, Gebauer G, Savolainen V, Barraclough TG, Pauw A (2011) The effects of above- and below-ground mutualisms on orchid speciation and coexistence. Am Nat 177(2):E54-E68 
Wells TCE, Rothery P, Cox R, Bamford S (1998) Flowering dynamics of Orchis morio L. and Herminium monorchis (L.) R.Br. at two sites in eastern England. Bot J Linn Soc 126:39-48
Wright IJ, Reich PB, Westoby M et al (2004) The worldwide leaf economics spectrum. Nature 428:821-827 